\title{
Conservational Architecture evaluation and environmental control system based on long-term environmental monitoring data___Taking Guangyuan Qianfoya Cliff Inscriptions Conservational Architecture assessment as an example
}

\author{
Rong Zhang ${ }^{1}$, Qi Wang ${ }^{1}$, Zhuyin Chen ${ }^{1}$, Cheng An $^{2}$ \\ ${ }^{1}$ Cultural Heritage Conservation Center Beijing GWY Co. Ltd., People's Republic of China \\ ${ }^{2}$ Technical Research and Development Department, Instrumentation Technology \& Economy Institute
}

KEY WORDS: environmental monitoring, conservation architecture evaluation, hierarchical micro-environmental control threshold

\begin{abstract}
:
The environmental monitoring data of Qianfoya Cliff Inscriptions in Guangyuan, Sichuan Province accumulated since 2014 make it possible to analyze the environmental monitoring data in and out of the Experimental Structure of the Conservational Architecture of Qianfoya Cliff Inscriptions which was built in 2016. By comparing the long-term environmental pattern and differences between the internal and external part of the section, the results indicate that the Conservational Architecture effectively decrease the frequency of short-term sever winds, strong sunshine and extreme high and low temperatures, reduces the short-term temperature and humidity variation range, which creates a stable microenvironment conducive to the preservation of statues without changing the long-term environmental transformation pattern. Moreover, a parameter system for evaluating the conservational architecture, which directly related to environmental damage factors and meets the requirement of measurability and controllability, has been established and control threshold of microenvironment adjustment, which divides abnormal environment state in three levels (caution states, Pre-warning states, Warning states), has been chosen so as to quantitatively evaluate the protection effect of the experimental structure and provide data guidance for daily protection work and environmental control. Based on this parameter system and control thresholds, the total duration of warning states in Qianfoya experimental structure can be reduced by $30 \%$ compared with that outside the experimental structure, which further proves that the experimental structure plays a significant role in alleviating the main natural deterioration factors in Qianfoya cliff.
\end{abstract}

\section{INSTRUCTION}

Qianfoya (the thousand Buddha cliff) Cliff Inscriptions in Guangyuan, Sichuan Province dating back to about 1700 years ago, which are of great historical value artistic and aesthetic value, have suffered from heavily weathering. In order to fully understand the causes of damage to cultural relics, slow down the weathering of the grottoes and develop scientific conservation measures, long-term monitoring and data analysis of the meteorological environment of Qianfoya and the microenvironment of each cave was launched in 2014. According to preliminary data, the main damaging factors of Qianfoya are drifting rain and accumulated water on the cliff, strong valley winds and severe sunlight. In order to verify the effectiveness of conservation architecture for Qianfoya, an experimental structure of the conservation architecture was constructed on the north side of the cliff to protect it from rain, sunlight and strong winds. Steel structure and tile-curtain system are adopted to create a stable microenvironment while ensuring ventilation. The monitoring of environmental elements inside and outside the experimental structure is used to assess the impact of the experimental structure on the meteorological and cave niche micro environmental conditions of the cliff, in addition to providing basic data for the design and construction of the overall cliff conservation architecture. 


\section{ANALYSIS AND CONCLUSION OF ENVIRONMENT MONITORING DATA}

\subsection{Overview of climate and environment}

Generally speaking, the average daily relative humidity and temperature in summer are higher, while the daily variation range is relatively small. The $\mathrm{RH}$ varies greatly from day to day. When there is no rain or snow in winter, the average daily relative humidity could also be high. Most of rain falls in summer and autumn as rainstorm instead of continuous rain while less falls in other seasons.

Carving on sandstones which is mainly cemented by gypsum, the Cliff Inscriptions are easily affected by dry-wet cycle. The migration of water vapor inside the cliff, the rainwater runoff on the cliff and the change of water vapor in the air may all cause hydration and dehydration of gypsum, which lead to the change of gypsum volume, thus destroying the microstructure of the rock.

Facing to the west, the Cliff Inscriptions will be seriously affected by the sun, which leads to drastic changes in rock surface temperature, resulting in stress difference between surface and the internal part of the rocks. Day by day, statues and inscriptions of the shallow niches and the opening of deep caves will be seriously damaged.

The mainstream winds of Qianfoya Cliff Inscriptions are north wind and northeast wind. The north wind is the common monsoon wind in autumn and winter in China, while the northeast wind is the valley wind along the river valley. The mainstream winds with dust particles will directly impact weathered surface rock mass, resulting in the fragile and precious surface rock mass completely peeling off.

However, we also find that there is a certain coupling relationship between wind speed and humidity at the same time, that proper ventilation is conducive to reducing the extremely high humidity.

\subsection{Microenvironment of the Caves}

The microenvironment of different caves and niches of Qianfoya is quite different. The temperature and humidity of shallow caves and niches, which are greatly affected by mountain wind and sunshine, usually change dramatically. The temperature difference on the rock surface is large and the preservation conditions are poor. The temperature, humidity and rock surface temperature of deep caves which are not easily affected by water, sunlight and wind are usually stable. Deep caves are often well preserved, and extreme temperature and humidity are less likely to occur. However, the overall change trend of temperature and humidity parameters of deep caves and shallow niches is basically consistent and synchronized with the environmental temperature and humidity. For a single cave, the environmental stability of the inner wall is higher than that of the outer wall, and the east side is higher than that of the west side.

Therefore, it is safe and feasible to simulate the preservation environment of deep caves in niches. Firstly, by comparing the present situation and microenvironment of different caves, it is proved that the preservation environment conditions of deep caves are really beneficial to the preservation, and will not cause sudden environmental changes; Secondly, the preservation condition of the deep cave is a prevailing microenvironment in Qianfoya Cliff area, which makes it technically feasible to approach the preservation condition of the deep cave as close as possible.

Above all, the overall environment of Qianfoya Cliff is stable in temperature and humidity, which is good for preservation. Proper designed conservation architecture can maintain rock temperature, prevent excessive temperature difference between day and night, reduce extreme high and low humidity, reduce frequent water and salt reciprocating migration and cementation loss on the surface of rocks, and balance the water content at different depths, finally providing a relatively stable environmental preservation state without breaking the thermal, moisture and diffusion balance between stone and the microenvironment,.

\subsection{Conservational Architecture monitoring result}

After the experimental structure of conservation architecture was built up, many years' data, including temperature and humidity, rock surface temperature, wind speed and etc. were compared between the inside and outside of the experimental structure.

Introduction of monitoring sites

138\# The cave is relatively deep and located in the upper part of the cliff; The monitoring site is located inside the cave

512\# The cave is deep and located in the middle of the cliff; The monitoring site is located inside the cave

431\# The niche is very shallow and located in the middle of 
the cliff.

806\# The cave is deep and located in the middle of the cliff; The monitoring site is at the front of the south side of the cave, near the entrance.

834 The niche e is very shallow and located in the lower part of the cliff.

535\# The cave is deep and located in the the lower part of the cliff; The monitoring site is located inside the cave

Table 1 Overview of monitoring sites

\begin{tabular}{lll}
\hline \multicolumn{1}{c}{ wind speed $(\mathrm{m} / \mathrm{s})$} & Average & Maximum \\
\hline Inside the Experimental Structure & 0.32 & 3.91 \\
Outside the Experimental Structure & 1.26 & 6.90 \\
\hline
\end{tabular}

Table 2 wind speed comparison in 2017

The Experimental Structure of the conservation architecture significantly reduces the wind speed in the short term from $6.9 \mathrm{~m} / \mathrm{s}$ to $3.91 \mathrm{~m} / \mathrm{s}$ at the same time. (As Table 2 )

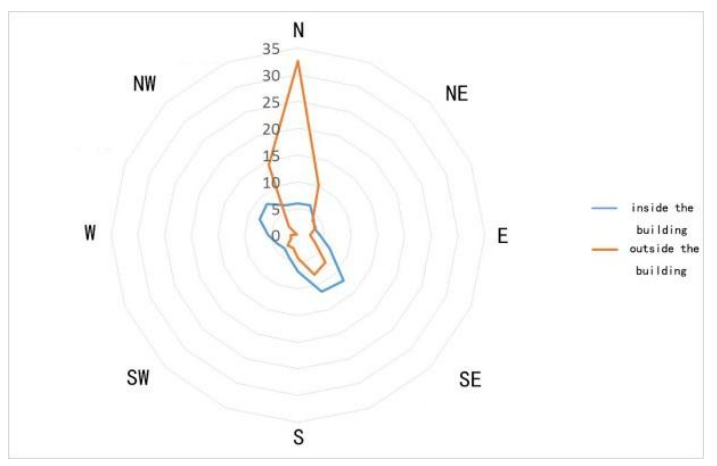

Figure 1 Wind direction diagram inside and outside the experimental structure

The experimental structure has achieved good results in two aspects: wind direction improvement and wind speed control. Specifically, the average wind speed in a long period of time decreased from $1.26 \mathrm{~m} / \mathrm{s}$ to $0.32 \mathrm{~m} / \mathrm{s}$, which decreased by three-quarters of the original average wind speed; The wind direction has also been improved from the situation that the north wind dominates and the frequency of the north wind exceeds $30 \%$ when there is no experimental structure, to the situation that the wind was diverted to all directions and the frequency of the each directions is about $5-10 \%$.

As far as the regional wind environment is concerned, the experimental structure has played a role in reducing the high wind, stabilizing the wind speed, and diverting the north wind to other directions.

\begin{tabular}{lllll}
\hline & Max & Average & stdev & C. V \\
\hline Experimental Structure & 4.5 & 0.34 & 0.41 & 1.21 \\
$138 \#$ & 6.8 & 0.48 & 0.63 & 1.32 \\
$512 \#$ & 4 & 0.19 & 0.3 & 1.6 \\
$431 \#$ & 17.4 & 1.68 & 1.62 & 0.96 \\
$806 \#$ & 8.5 & 1.02 & 0.92 & 0.9 \\
$834 \#$ & 10 & 1.31 & 1.1 & 0.84 \\
$535 \#$ & 3.8 & 0.3 & 0.37 & 1.23 \\
\hline
\end{tabular}

Table 3 Summary of wind speed of Experimental Structure and different caves

By comparing the micro environmental data of each cave, it can be seen that the maximum and average wind speeds in the experimental structure are significantly smaller than those measured in the shallow niches 431\# and 834\#, while they are the same as those in the deeper niches of 512\# Cave, 535\# Cave and 138\# Cave. Therefore, it can be concluded that the experimental structure provides a wind environment similar to a deep cave niche with stable and low wind speeds.

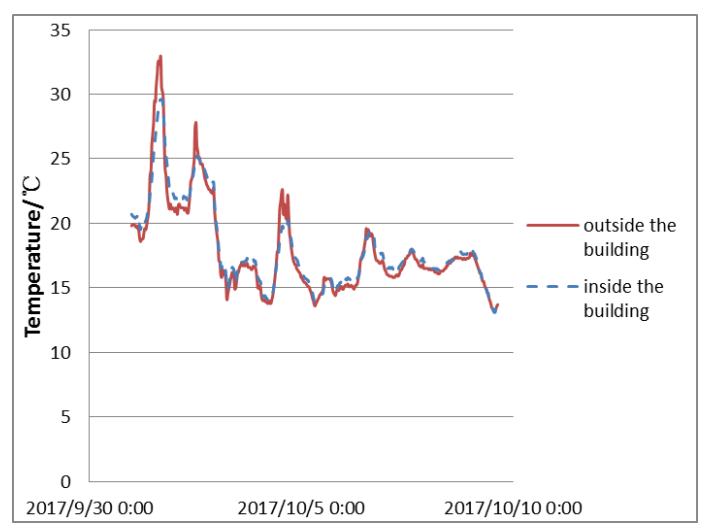

Figure 2 Comparison of temperature of microenvironment inside and outside the experimental structure

Figure 2 shows that the difference between the air temperature inside and outside the experimental structure. The main trend is the same while the overall temperature inside the experimental structure is slightly lower in comparison.

The solar radiation during the daytime does not hit directly on the rock, but first hits on the roof and tile curtain wall of the conservational architecture then conducts heat to the rock through thermal radiation and convection, which actually curbs the direct heating of the rock surface by solar radiation. Meanwhile, wind speed goes relatively high outside the tile curtain of experimental structure and air between the tiles dissipate heat and carry it away directly by wind, so that the 
temperature inside the tile curtain wall can be cool.

Moreover the temperature on the inner surface of the tiles at night is also much higher than the equivalent temperature of a clear sky, which means that the heat lost by the rock body at night due to the radiation effect will be relatively reduced.

Combining the effects of daytime and nighttime, it can be found that the conservation architecture plays a great role in maintaining the temperature of the rock body and preventing excessive temperature difference between day and night.

\begin{tabular}{llllll}
\hline & Max & Min & Average & stdev & C. V \\
\hline $\begin{array}{l}\text { Experimental } \\
\text { Structure }\end{array}$ & 36.5 & -1.6 & 18 & 8.18 & 0.45 \\
$138 \#$ & & & & & \\
$512 \#$ & 42.6 & -3.9 & 18.1 & 8.26 & 0.46 \\
$431 \#$ & 37.3 & -4.2 & 18.1 & 8 & 0.44 \\
$806 \#$ & 40.1 & -5.1 & 17.9 & 8.53 & 0.48 \\
$834 \#$ & 34.1 & -3 & 17.9 & 7.7 & 0.43 \\
$535 \#$ & 44.5 & -4.6 & 18.2 & 8.62 & 0.47 \\
\hline
\end{tabular}

Table 4 Summary of temperature in and outside the Experimental Structure

The average air temperature in the Experimental Structure is essentially the same as in the niches and caves outside, which indicates that the Experimental Structure does not break the basic thermal equilibrium between the artifacts and microenvironment. The maximum temperature within the experimental structure is lower and the minimum temperature is higher than that of shallow niches, and the maximum temperature within the experimental structure is lower and the minimum temperature is higher than that of the deep caves, while the standard deviation and coefficient of variation are similar. This suggests that the experimental structure provides a thermal environment similar to that of deep caves, avoiding extreme high and low temperatures and even more stable.

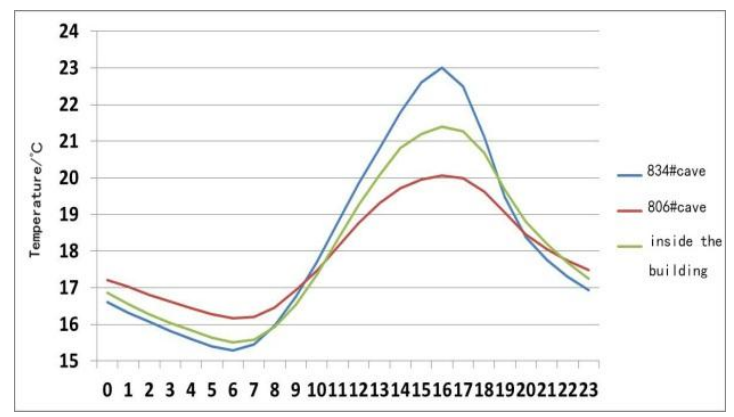

Figure 3 Time by time comparison of large data of temperature inside and outside the experimental structure
The time-by-time comparison of monitoring data in Figure 3 shows that the thermal environment in the experimental structure is statistically similar to that in deep caves with delayed temperature peaks and smaller temperature fluctuations than that in niches.

The average absolute humidity of the air in the experimental structure is basically the same as that of the niches and caves outside the structure, which indicates that the experimental structure does not break the vapor diffusion equilibrium between the artifacts and environment. The coefficient of variation of absolute humidity in the experimental structures is the smallest and the maximum value of absolute humidity in the experimental structure is moderately low among the monitored caves, indicating that the microenvironment in the experimental structure is relatively dry in the Qianfo Cliff area.

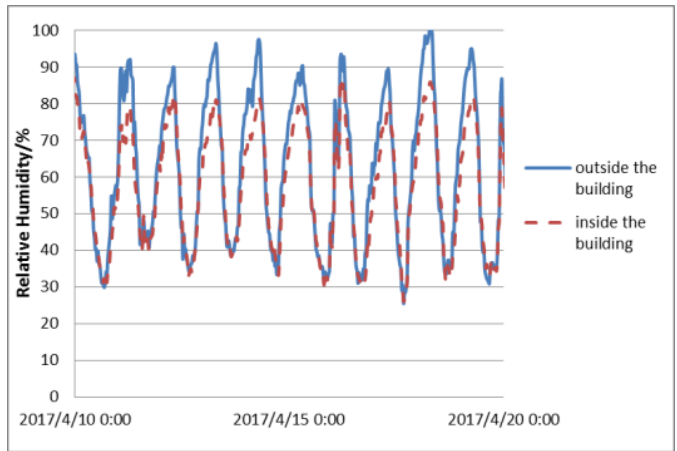

Figure 4 Comparison of relative humidity of microenvironment inside and outside the experimental structure

As can be seen in Figure 4, during the daytime when the relative humidity is low, there is basically no difference in the relative humidity of inside and outside the experimental structure; during the rainfall period or at night when the relative humidity is high, the relative humidity inside the experimental structure is significantly lower than that outside the experimental structure. In other words, the experimental structure though has little effect on the minimum value, $t$ reduces the maximum value of relative humidity to a certain extent.

All in all, since the cliff inscriptions suffered less from underground water (Zong, 2011), there is a great chance to preserve the cliff inscriptions safely by conservational architecture. The microenvironment of caves and niches could be quite different. The shallow niche, which is greatly affected by mountain wind and sunshine, suffers from the large 
temperature difference on the surface so that preservation condition is poor. The deep caves, which are not directly affected by water, sunshine and wind, are stable in environment and well preserved. Therefore, the environmental temperature and humidity of Qianfo Cliff are stable and have good preservation conditions. Without breaking the thermal, moisture and diffusion equilibrium between the cultural relics and the microenvironment, the conservation architecture (experimental structure) can maintain the rock temperature, prevent excessive temperature differences between day and night, reduce extreme high and low humidity, reduce frequent water and salt migration and cement loss from the surface of rocks, and balance the water content at different depths, thus providing a relatively stable environmental preservation state for cultural relics

\section{EVALUATION PARAMETER SYSTEM}

\subsection{Parameter system}

A large number of parameters related to the environmental damage factors of Qianfoya cliff was sort out by environmental monitoring. In order to ensure the applicability of the evaluation system, the parameters in the system should be classified according to the measurability and controllability of parameters, and at the same time be graded according to the correlation between the parameters and the key damage factors. Core parameter, which is easy to test and directly related to the deterioration. It includes the temperature of air and the surface of rocks, RH, wind speed, the sun radiation and Air pollutants.

\section{Observation parameter and regular inspection parameter,} which is the phenomenon of environmental change instead of the fundamental factor of environmental change. It cannot be measured directly or is not suitable for frequent measurement. The observation parameter can generally be converted or extrapolated from the core control indicators; regular inspection parameters are those that are tested every 5-10 years.

\subsection{Threshold value of the parameter}

The core parameters are the main monitoring elements in practical work, as well as the main reference for taking environmental adjustment measures. Therefore, in order to meet the needs of hierarchical regulation and control of protective measures in practical work, three-level thresholds of core parameters have been set, corresponding to the four preservation conditions of cultural relics:

Normal conditions: at this condition, the cultural relics are considered to be in a stable state for a long time with little risk of conservation; it should account for more than $67 \%$ of the total duration of the year.

Attention conditions: administrator should pay attention that the environmental conditions may have destructive impact to the Cliff Inscriptions. Some further evaluation should be made.

Pre-warning conditions: $t$ the environmental conditions at this time are destructive and measures to improve them should be considered.

Warning conditions: the cultural relics are in an extreme state at this time. The adverse effects on the cultural relics under this condition may be far greater than the accumulation of many years under normal circumstances. Measures should be taken to improve it as soon as possible.

The Attention conditions, Pre-warning conditions and Warning conditions can be collectively referred to as abnormal conditions

The hierarchical control threshold system taking the predictability and accuracy of the early warning of cultural relics protection status into account, provides administrators with a basis for evaluating preservation environment conditions, and at the same time gives administrators time for observation and decision-making, so that the implementation of management and intervention measures is more scientific and orderly.

Due to the data distribution of different parameters, the three-level threshold is divided in different ways according to the actual monitoring situation of each parameter

\subsubsection{Temperature}

Within a certain period of time, the distribution of temperature monitoring data conforms to the normal distribution. In order to take into account the convenience and accuracy of parameter use, statistics are performed on a monthly basis. Referring to " $3 \sigma$ " mode in statistics, the three-level threshold of temperature can be set as follows: 


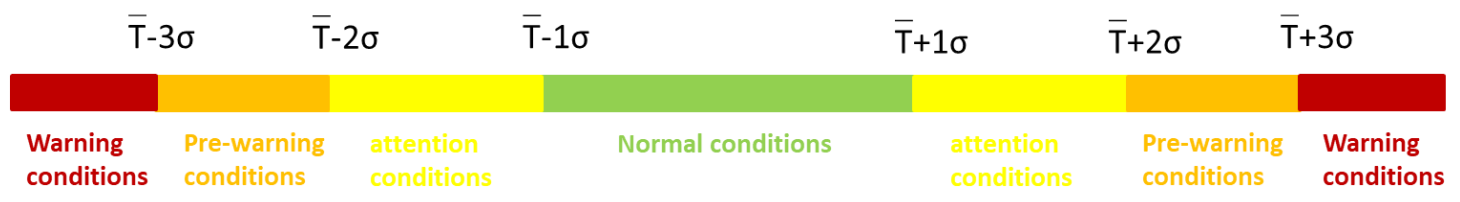

Figure 5 thresholds setting method of temperature

\begin{tabular}{lllll}
\hline & Normal conditions & Attention conditions & Pre-warning conditions & Warning conditions \\
\hline Jan & {$[3.86,7.72]$} & {$[1.93,3.86),(7.72,9.65]$} & {$[-4.19,1.93),(9.65,11.58]$} & $(\infty,-4.19),(11.58, \infty)$ \\
Feb & {$[5.16,10.42]$} & {$[2.53,5.16),(10.42,13.05]$} & {$[-5.19,2.53),(13.05,15.68]$} & $(\infty,-5.19),(15.68, \infty)$ \\
Mar & {$[11.29,16.15]$} & {$[8.86,11.29),(16.15,18.58]$} & {$[1.32,8.86),(18.58,21.00]$} & $(\infty, 1.32),(21.00, \infty)$ \\
Apr & {$[14.39,20.14]$} & {$[11.52,14.39),(20.14,23.01]$} & {$[1.98,11.52),(23.01,25.89]$} & $(\infty, 1.98),(25.89, \infty)$ \\
May & {$[17.73,23.16]$} & {$[15.02,17.73),(23.16,25.87]$} & {$[7.27,15.02),(25.87,28.58]$} & $(\infty, 7.27),(28.58, \infty)$ \\
Jun & {$[20.25,25.26]$} & {$[17.75,20.25),(25.26,27.77]$} & {$[10.58,17.75),(27.77,30.28]$} & $(\infty, 10.58),(30.28, \infty)$ \\
Jul & {$[20.76,25.28]$} & {$[18.50,20.76),(25.28,27.55]$} & {$[12.22,18.50),(27.55,29.81]$} & $(\infty, 12.22),(29.81, \infty)$ \\
Aug & {$[23.08,27.97]$} & {$[20.63,23.08),(27.97,30.42]$} & {$[14.36,20.63),(30.42,32.87]$} & $(\infty, 14.36),(32.87, \infty)$ \\
Sep & {$[18.40,23.11]$} & {$[16.05,18.40),(23.11,25.46]$} & {$[9.24,16.05),(25.46,27.82]$} & $(\infty, 9.24),(27.82, \infty)$ \\
Oct & {$[14.23,17.53]$} & {$[12.57,14.23),(17.53,19.19]$} & {$[7.64,12.57),(19.19,20.84]$} & $(\infty, 7.64),(20.84, \infty)$ \\
Nov & {$[9.57,13.41]$} & {$[7.64,9.57),(13.41,15.33]$} & {$[2.53,7.64),(15.33,17.25]$} & $(\infty, 2.53),(17.25, \infty)$ \\
Dec & {$[5.27,9.34]$} & {$[3.24,5.27),(9.34,11.37]$} & {$[-3.10,3.24),(11.37,13.41]$} & $(\infty,-3.10),(13.41, \infty)$ \\
\hline
\end{tabular}

Table 5 The thresholds values of temperature $\left({ }^{\circ} \mathrm{C}\right)$

\subsubsection{Humidity}

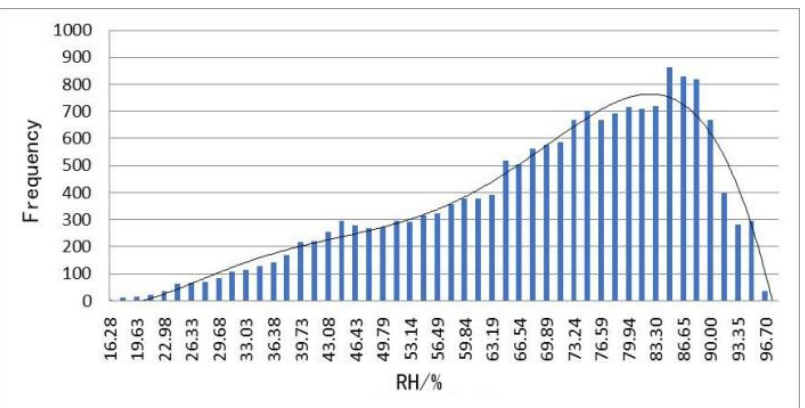

\section{Figure 6 RH Distribution}

As can be seen from the above graph, the humidity conforms to a skewed distribution, favoring the side of high humidity with a median above $70 \%$ and a mode even close to $85 \%$. It can be assumed that there is a prominent risk of degradation by microorganisms under normal conditions.

Therefore, combining the " $3 \sigma$ " mode with the actual situation, different threshold determination methods are proposed for the upper and lower thresholds-the lower limits of the humidity threshold follow the same pattern as that of temperature while the upper limit of the humidity thresholds are as follow:

Upper limit of normal condition is the value that is repeated most often in the data set.

Upper limit of attention condition is the value at the percentage decided by formula follows:

$$
\mathbf{P}_{\mathbf{a}}=\mathbf{P}_{(\leq M)}+\frac{\left(100 \%-\mathbf{P}_{(>M)}\right)}{3}
$$

Upper limit of pre-warning condition is the value at the percentage decided by formula follows:

$$
\mathbf{P}_{\mathrm{W}}=\mathbf{P}_{(\leq M)}+\frac{2\left(100 \%-\mathbf{P}_{(>M)}\right)}{3},
$$

Where: $\mathrm{M}=$ the mode of RH data

$\mathbf{P}_{(\leq M)}=$ the percentage of the value that is not greater than the mode

$\mathbf{P}_{(>M)}=$ the percentage of the value that is greater than the mode

\begin{tabular}{llll}
\hline $\begin{array}{l}\text { Normal } \\
\text { conditions }\end{array}$ & $\begin{array}{l}\text { Attention } \\
\text { conditions }\end{array}$ & $\begin{array}{l}\text { Pre-warning } \\
\text { conditions }\end{array}$ & $\begin{array}{l}\text { Warning } \\
\text { conditions }\end{array}$ \\
\hline$[51.92,84.70]$ & {$[34.86,51.92),($} & {$[17.79,34.86),($} & $(\infty, 17.79),(90$. \\
& $84.70,86.65]$ & $86.65,90.00]$ & $00, \infty)$ \\
\hline
\end{tabular}

Table 6 The thresholds values of $\mathrm{RH}(\%)$ 


\subsubsection{Wind speed}

Wind speed does not show obvious periodicity and regularity in monitoring.

As the overall distribution of wind speed in Qianfoya is similar to the half-normal distribution with static wind frequency as the axis of symmetry. The average wind speed is relatively small, mainly concentrated below $1 \mathrm{~m} / \mathrm{s}$ except for the static wind, but high wind speed occasionally occurred. In view of the distribution characteristics and the randomness of extreme wind speeds, thresholds are as followed:

The upper limit of normal conditions is the value not greater than $5 \%$ of data; The upper limit of attention conditions is the value not greater than $3 \%$ of data. The upper limit of pre-warning conditions is the maximum data.

\begin{tabular}{cccc}
$\begin{array}{c}\text { Normal } \\
\text { conditions }\end{array}$ & $\begin{array}{c}\text { Attention } \\
\text { conditions }\end{array}$ & $\begin{array}{c}\text { Pre-warning } \\
\text { conditions }\end{array}$ & $\begin{array}{c}\text { Warning } \\
\text { conditions }\end{array}$ \\
\hline & & & \\
$(\infty, 3.49]$ & $(3.49,4.04]$ & $(4.04,9.00]$ & $(9.00, \infty)$ \\
\hline
\end{tabular}

Table 7 The thresholds values of wind speed $(\mathrm{m} / \mathrm{s})$

\section{EVALUATION RESULTS OF THE EXPERIMENTAL STRUCTURE OF CONSERVATIONAL} ARCHITECTURE

Using the hierarchical parameter system can count the frequency of environmental conditions at all levels, thereby quantitatively describing the effect of the experimental structure and the differences in the microenvironment among caves and niches.

\begin{tabular}{ccccc}
\hline & \multicolumn{4}{c}{ Duration of abnormal conditions of wind } \\
& \multicolumn{4}{c}{ speed/hours } \\
\cline { 2 - 5 } & $\begin{array}{c}\text { Attention } \\
\text { conditions }\end{array}$ & $\begin{array}{c}\text { Pre-warning } \\
\text { conditions }\end{array}$ & $\begin{array}{c}\text { Warning } \\
\text { conditions }\end{array}$ & Total \\
\hline $535 \#$ & 0 & 0 & 0 & 0 \\
$512 \#$ & 0 & 0 & 0 & 0 \\
Experimental & 3 & 0 & 0 & 3 \\
Structure & & & & \\
$138 \#$ & 31 & 18 & 3 & 52 \\
\hline
\end{tabular}

\begin{abstract}
$806 \#$
\end{abstract}
12\#

287

834\#

382

121

783

431\#

915

830

784

Table 8 Duration of abnormal conditions of wind speed in hours

According to the monitoring data in 2018 , both the maximum wind speed and the frequency of high wind speeds in shallow niches are higher than those in deep caves, while the monitoring points at the openings of deep caves are somewhere in between. The maximum annual wind speed dropped from $10.6 \mathrm{~m} / \mathrm{s}$ outside the experimental structure to $4.2 \mathrm{~m} / \mathrm{s}$. The monitoring data is compared with the frequency of one data per hour. There is no data of the deep cave in abnormal condition, while the total account of data in the abnormal condition in the shallow cave niche exceeds 500, with the worst exceeding 2500. The total account of less deep caves and the monitoring points located at the opening of the deep caves in abnormal condition are only 313 at the highest. The data in abnormal condition inside the experimental structure counts only 3 , and the total amount fell between the monitoring points of relatively deep caves and the deep caves. At the same time, there was no data of the experimental structure fell in pre-warning condition and warning condition, which were very close to the preservation conditions of the monitoring points of the deep caves during the same period.

Comparing the monitoring data of environmental humidity, it can be found that the frequency of the humidity data fell in abnormal condition at a monitoring point is generally higher than that of temperature data fell in abnormal condition.

\begin{tabular}{ccccc}
\hline & \multicolumn{4}{c}{ Duration of abnormal conditions of RH } \\
& \multicolumn{4}{c}{ /hours } \\
\cline { 2 - 5 } & $\begin{array}{c}\text { Attention } \\
\text { conditions }\end{array}$ & $\begin{array}{c}\text { Pre-warning } \\
\text { conditions }\end{array}$ & Warn-ing & Total \\
& 1054 & 529 & 600.5 & 2183.5 \\
\hline $806 \#$ & & & & \\
Experimental & 1188 & 622.5 & 466 & 2276.5 \\
Structure & & & & \\
138\# & 1475.5 & 699 & 396.5 & 2571 \\
& & & & \\
\hline
\end{tabular}


The International Archives of the Photogrammetry, Remote Sensing and Spatial Information Sciences, Volume XLVI-M-1-2021 28th CIPA Symposium “Great Learning \& Digital Emotion”, 28 August-1 September 2021, Beijing, China

\begin{tabular}{ccccc}
$12 \#$ & 1575 & 744 & 383.5 & 2702.5 \\
$535 \#$ & 1487 & 834 & 544 & 2865 \\
$512 \#$ & 1567.5 & 792.5 & 723 & 3083 \\
$834 \#$ & 1751 & 1099.5 & 513 & 3363.5 \\
& & & & \\
$431 \#$ & 1628.5 & 782.5 & 1125 & 3536 \\
\hline
\end{tabular}

Table 9 Duration of abnormal conditions of RH in hours

Unlike the case of air temperature in the microenvironment, the time distribution of relative air humidity across conditions showed that the duration of the abnormal condition was longer in the shallow niche while shorter in the deep cave. The total time of the abnormal condition of relative air humidity in caves and niches is also longer than that of the air temperature in caves and niches.

The exceptionally superior humidity environment of shallow caves and niches shows the contradictory relationship between wind speed and environmental humidity: high-speed northwest wind may cause wind erosion to cliff walls, but at the same time air flow is beneficial to divert moisture rapidly to reduce extreme high humidity.

The probability of abnormal conditions in the experimental structure is significantly lower than that of a shallow niche, slightlyl higher than a deep niche, and the distribution ratio of the comparison of the three conditions is consistent with most of caves: the period in Attention conditions is the longest, that in Pre-warning conditions is second, and that in Warning conditions is shortest. It shows that the experimental structure as a whole reduces the frequency of excessively low and excessively high humidity without changing the overall distribution pattern of humidity, and finds a good balance point between air fluidity and environmental humidity. It can be said that the experimental structure has become one of the areas with the best humidity conditions in Qianfoya cliff.

\begin{tabular}{lcccc}
\hline \multicolumn{5}{c}{ Duration of abnormal conditions of } \\
& Temperature /hours & & \\
\cline { 2 - 5 } & $\begin{array}{c}\text { Attention } \\
\text { conditions }\end{array}$ & $\begin{array}{c}\text { Pre-warning } \\
\text { conditions }\end{array}$ & $\begin{array}{c}\text { Warning } \\
\text { conditions }\end{array}$ & Total \\
\hline $806 \#$ & 1127 & 203.5 & 0 & 1330.5 \\
$512 \#$ & 1288.5 & 140.5 & 0 & 1429 \\
\hline
\end{tabular}




\section{CONCLUSION}

Continuous environmental monitoring over many years reveals significant differences in the microenvironment between different cave niches, that deep caves have lower average wind speed and better environmental stability than shallow niches in not only air temperature and humidity but also rock surface temperature. Meanwhile the statues in the deep caves were better preserved and less weathered than the shallow niches, suggesting that the micro environmental conditions constructed in the deep caves were favorable to reduce statue weathering in the humid and windy environment of the river valley terrain in the Qianfoya area. It is safe to the relics and technically feasible to simulate micro environmental conditions in the deep caves that exist in the Qianfoya cliff area by constructing protective structures to reduce the damage to cultural relics from the natural environment.

Hierarchical micro-environmental control threshold were designed for the core control parameter including temperature, humidity, and wind speed based on the monitoring data. It proves that the system can quantitatively assess the environmental stability of different caves, and the results of the preservation environmental stability assessment of each cave and niche are basically consistent with the results of the preliminary result of environment monitor.

Based on the hierarchical micro-environmental control threshold system, the conservation architecture showed good environmental control effects, and the frequency of extreme environmental conditions was reduced by over $30 \%$ compared with that outside the experimental structure. The conservation architecture simulated the preservation conditions of the original deep cave on the cliff wall, reducing the environmental factors that led to the destruction of the statue.

There are many other statistical methods of outlier delineation, and this paper only provides an attempt at threshold setting, with much room for refinement. Furthermore, as the monitoring data accumulate, the grading warning model embedded in the monitoring system can be established to improve the graded control threshold system for environmental protection in Qianfo Cliff.

\section{REFERENCES}

Guang-hai, C.. (2017). The Experimental Structure of the Conservational Architecture of Qianfoya Cliff Inscriptions.
Architectural Worlds (4).

Jing-ting, Z. , Shu-li, W. , \& Zhong-yong, Z. . (2011). Study on Environmental Geology Problem of Surface Weathering of Grotto Statues in Guangyuan Qianfoya,Sichuan. (02), 79-84. 